\title{
Impact of changes in metabolic control on progression to photocoagulation for clinically significant macular oedema: a 20 year study of type 1 diabetes
}

\author{
B. Sander • M. Larsen • E. W. Andersen • \\ H. Lund-Andersen
}

Received: 28 January 2013 / Accepted: 17 July 2013 / Published online: 30 August 2013

(C) The Author(s) 2013. This article is published with open access at Springerlink.com

\begin{abstract}
Aims/hypothesis Although increasing hyperglycaemia, arterial hypertension and longer duration of diabetes raise the risk of progression of diabetic retinopathy, short-term benefits in terms of improved metabolic control and lowered blood pressure have not been demonstrated. We therefore examined the effect of changes in glycaemia and arterial blood pressure on the incidence of clinically significant macular oedema in a population of diabetic patients.

Methods We performed a retrospective review of all patients with type 1 diabetes who attended the retinopathy screening clinic at the Steno Diabetes Center from 1988 to 2008, using the endpoint referral to first photocoagulation treatment for clinically significant diabetic macular oedema. The analysis included 1,878 patients (median observation, 8 years). Changes were defined as the inter-visit change; in the case of an event the last event-free interval before referral, where the median screening interval was 6 months.

Results Risk of progression to photocoagulation for macular oedema increased with duration of diabetes $(p<0.001)$, current $\mathrm{HbA}_{1 \mathrm{c}}(p<0.0001)$ and with the magnitude of changes in $\mathrm{HbA}_{1 \mathrm{c}}(p=0.0002)$ and systolic blood pressure $(p<0.0001)$ in a multiple regression model. A recent decrease of $\geq 0.5$ percentage points or an increase in $\mathrm{HbA}_{1 \mathrm{c}}$ of $>0.5$ percentage points per 6 months was associated with HRs of 3.04 and 1.28 , respectively, compared with lesser changes in $\mathrm{HbA}_{1 \mathrm{c}}$.
\end{abstract}

\footnotetext{
B. Sander $(\triangle) \cdot M$. Larsen $\cdot$ H. Lund-Andersen

Department of Ophthalmology, Glostrup Hospital, University

of Copenhagen, Ndr. Ringvej 57, 2600 Glostrup, Denmark

e-mail: bisan@regionh.dk

E. W. Andersen

Statistics and Data Analysis, Technical University of Copenhagen,

Lyngby, Denmark

H. Lund-Andersen

Steno Diabetes Center, Gentofte, Denmark
}

Conclusions/interpretation In this study, large recent changes in metabolic control and systolic blood pressure, irrespective of direction, were independent risk factors for progression to photocoagulation for diabetic macular oedema. The effects of metabolic and haemodynamic stability on diabetic retinopathy should be examined in prospective studies.

Keywords Blood pressure $\cdot$ Clinically significant macular oedema $\cdot \mathrm{HbA}_{1 \mathrm{c}} \cdot$ Risk factors $\cdot$ Type 1 diabetes

\section{Abbreviations \\ CSME Clinically significant macular oedema \\ ETDRS Early Treatment Diabetic Retinopathy Study}

\section{Introduction}

Diabetic macular oedema is a sight-threatening complication of diabetic retinopathy [1-4]. Risk factors identified in previous studies include duration of diabetes, hyperglycaemia, and arterial hypertension [2, 5-11]. The 25 year follow-up of the Wisconsin Epidemiological Study of Diabetic Retinopathy showed that both baseline glycaemia and an increase in glycaemia from baseline to year four were significant risk factors for progression to diabetic macular oedema [12].

In the DCCT the short-term response to intensified insulin treatment in type 1 diabetes was an accelerated progression of diabetic retinopathy. It was only after approximately one year that the rate of progression among patients on intensified insulin therapy fell below that of the conventional therapy group, where it remained for the duration of the 9 year study [13-15]. The observed progression events were largely subclinical. In addition, a later report has shown that the variability of metabolic regulation is associated with microvascular complications $[16,17]$. In the present study, we examined the effect 
of changes in metabolic control and blood pressure in a routine clinical setting on an outcome of clinical impact, namely photocoagulation for clinically significant macular oedema, in 1,878 patients with type 1 diabetes attending the diabetic retinopathy screening clinic of the Steno Diabetes Center.

\section{Methods}

Patients The study population consisted of all patients with type 1 diabetes who attended the diabetic retinopathy screening clinic at the Steno Diabetes Center between the initiation of systematic retinopathy screening in 1988 and the end of 2008, of which 50\% started screening before September 1993. The Steno Diabetes Center provides primary diabetes care for a large, geographically defined subset of patients with type 1 diabetes who reside in the greater Copenhagen area. Having type 1 diabetes was defined as undergoing insulin therapy and having received a diagnosis of diabetes before 30 years of age. Before 1996, the study population included children, whereas after 1996 only patients aged 16 years and older attended the clinic. Because diabetic retinopathy in general and diabetic macular oedema in particular are very rare in patients younger than 19 years this change in the composition of the study population is unlikely to impact study outcomes [10].

Screening procedure Retinopathy screening comprised, as a minimum, automated refractioning, determination of bestcorrected visual acuity, and mydriatic non-stereoscopic fundus photography. Stereoscopic fundus photography was used, however, up until the introduction of digital fundus photography in 2003. Retinopathy was graded and classified using the five-step Steno retinopathy scale, which assigns diabetic macular oedema to level 3 out of 5 [18]. The interval to the next screening examination was set as $3,6,12$ or 24 months, depending on severity of retinopathy as determined by the reviewing physician. Standard screening intervals were 2 years if no retinopathy was seen and decreasing with increasing severity of retinopathy. Ambiguous photographic findings and qualitatively unacceptable photographs led to patients being recalled for a slit-lamp biomicroscopy examination. From 2005 the screening procedure included transfoveal optical coherence tomography in eyes with macular lesions suggesting the presence of diabetic macular oedema.

\section{Procedure for diagnosis of clinically significant macular} oedema Routine procedure was for a physician to review the fundus photographs and to refer patients in need of or suspected of being in need of photocoagulation or other ophthalmic therapy to the Department of Ophthalmology at Glostrup Hospital (Herlev Hospital prior to 2006) where the decision to perform photocoagulation for diabetic macular oedema was based on slit-lamp biomicroscopic findings.
Fluorescein angiography was used only to assist the planning of photocoagulation therapy. Photocoagulation treatment criteria were based on the outcome of the Early Treatment Diabetic Retinopathy Study (ETDRS) and its definition of the treatment threshold 'clinically significant macular oedema' (CSME) [19, 20]. Deviations from these guidelines could be made at the treating physician's discretion when ocular, systemic or psychosocial conditions suggested it was relevant.

The study endpoint The endpoint was taken as the event of a patient progressing to the patient's first photocoagulation treatment for CSME. Photocoagulation, rather than photographic detection of oedema, was used as the endpoint because stereoscopic biomicroscopy was considered the gold standard diagnostic modality. The nominal date the endpoint was reached when the patient was referred from the Steno Diabetes Center (referral visit). Not all patients referred would be treated with photocoagulation and, therefore, the registration of an event was made when the patient returned to the screening programme at Steno. This procedure, together with our interest in the change in risk factor levels from one visit to the next, implies that patients with three visits or less were not eligible for the analysis.

During the period of observation, primary treatment for CSME other than photocoagulation was administered only within controlled clinical trials and in patients with isolated perifoveal sources of leakage who, in the opinion of the physician, could not be safely treated by photocoagulation. Incident macular oedema of a lesser severity than CSME was not examined in this study.

Inclusion criteria Inclusion criteria were: (1) having participated in the retinopathy screening programme between 1988 and 2008; (2) having been followed by retinopathy screening for at least 6 months; (3) using insulin; and (4) having been diagnosed with diabetes before the age of 30 years.

Exclusion criteria Prior photocoagulation for diabetic macular oedema was an exclusion criteria. In addition, patients with three or fewer visits at the screening clinic were excluded to ensure a meaningful period of observation, which reduced the study population from 2,324 to 1,878 patients. For patients included in the study, visits were excluded from analysis if the interval from the most recent previous visit was longer than 2.7 years, the $95 \%$ percentile for all screening intervals of the initial dataset, because the information about metabolic control and blood pressure at the most recent previous visit was deemed to be outdated. All following visits for that particular patient were also excluded from analysis. This criterion excluded 73 events in patients who had reached the endpoint of macular photocoagulation after an overdue screening visit, thus leaving 297 patients with an event out of 1,878 patients who were eligible for analysis. 
Systemic health Systemic health variables were retrieved from the electronic patient record system of the Steno Diabetes Center eye clinic. Visits within 1 week were regarded as one visit taking place on the earliest of the visit dates (this occurred for 30 patients). For most retinopathy screening visits, data from a systemic examination and blood tests were available from the same day. If not, such data were retrieved from the most recent endocrinology visit, provided that it was no more than 6 months previous to the retinopathy visit. Endocrinology visits were more frequent than retinopathy visits.

The analysis is based on the interval between visits as the analytical unit. Macular oedema develops over time, and must be regarded as present during an unknown fraction of the time between the visit where the patient is referred for photocoagulation and the previous visit. Inter-visit changes were defined as the differences between the observed values of the risk factors at the beginning of an interval (the current values) and the values at the beginning of the previous interval.

Changes were evaluated as inter-visit change between successive visits normalised to 6-monthly rates and analysed as class variables for the primary analysis. The classes were based on the quartiles for the event group, and owing to the approximate symmetry and distribution, rounded to the nearest 0.5 percentage point for changes in $\mathrm{HbA}_{1 \mathrm{c}}$ (corresponding to a change of $5.5 \mathrm{mmol} / \mathrm{mol}$ ), $10 \mathrm{mmHg}$ for changes in systolic blood pressure and $5 \mathrm{mmHg}$ for diastolic blood pressure. A total of 297 events was available for the analysis.

The reference range in healthy participants of the $\mathrm{HbA}_{1 \mathrm{c}}$ assay used at the Steno Diabetes Center was $4.1-6.4 \%$, corresponding to $21.3-46.4 \mathrm{mmol} / \mathrm{l}$.

Statistical analysis $\mathrm{HbA}_{1 \mathrm{c}}$, systolic blood pressure, diastolic blood pressure and the inter-visit changes to these variables were analysed as explanatory variables. Duration of diabetes was grouped into 10 year intervals (for Table 1), except duration $<20$ years, which constituted a single group because it contained few events. Onset of diabetes before or after puberty was calculated using age of onset of 12 years as cutoff $[21,22]$. Quantitative clinical data were analysed by nonparametric Wilcoxon tests and the $\chi^{2}$ test was used for qualitative data. For the level of retinopathy, eyes progressing to the event of photocoagulation were compared with the mean of right and left eyes in non-progressing patients.

The analysis of the effect of metabolic control was made using a discrete time proportional hazards model [23] assuming a constant hazard of an event in each interval. A binomial model was used with complementary log-log link and the interval length as offset variable [23]. This model was appropriate because of the interval censored data, variation in intervisit intervals, and time-dependent explanatory variables. In patients with events, all subsequent visits were deleted. Visits without events served as controls. Results are given as HRs for reaching the endpoint calculated from exponentiation of
Table 1 Development of clinically significant diabetic macular oedema in type 1 diabetic patients

\begin{tabular}{llllllll}
\hline Photocoagulation status & \multicolumn{3}{c}{ Duration of diabetes (years) } & \multicolumn{3}{c}{ Total } \\
\cline { 2 - 6 } & $0-19$ & $20-29$ & $30-39$ & $40-49$ & $\geq 50$ & \\
\hline $\begin{array}{l}\text { Never photocoagulated, } n \\
\text { Photocoagulated for CSME }\end{array}$ & 524 & 453 & 328 & 205 & 71 & 1,581 \\
$n$ & 27 & 101 & 100 & 52 & 17 & 297 \\
Percentage of total & 4.9 & 18.2 & 23.4 & 20.2 & 19.3 & 15.8 \\
\hline
\end{tabular}

The table shows patients who reached their first referral for photocoagulation for CSME by duration of diabetes at the time of the event and the number of patients without CSME with the same duration of diabetes at his or her most recent visit

estimates. The model evaluated the outcome of photocoagulation for CSME and included as explanatory variables, in addition to what has been described above, the calendar period categorised into 5 -year groups. The purpose was to adjust for changes in procedures and practice during the period of observation, in particular for the earliest part, where the distinction between progression to photocoagulation for macular oedema and progression to photocoagulation for proliferations was less accurate.

Covariates in the discrete time proportional hazards model were entered as continuous variables and it was tested whether the effects could be included as linear or squared, otherwise they were entered as categorical variables as described above. $\mathrm{The} \mathrm{HbA}_{1 \mathrm{c}}$ and blood pressure variables were analysed one by one in univariate models adjusted for age, diabetes duration and calendar period (1988-1992, 1993-1997, 1998-2002 and 2003-2008). Subsequently, they were also tested in a multiple regression model.

There are missing values for the covariates. The main analysis was based on the available data and, in addition, a sensitivity analysis was carried out using multiple imputation. Missing values were imputed using chained questions when $\mathrm{HbA}_{1 \mathrm{c}}$ or blood pressure values were missing for an eye examination without an accompanying endocrinology examination. The procedure uses a sequence of univariate imputation methods with fully conditional specification of prediction equations; in all six complete datasets the missing blood pressure and $\mathrm{HbA}_{1 \mathrm{c}}$ values were imputed and the change in risk factors were calculated as for the original data.

In a separate analysis, the inter-visit changes were analysed as continuous variables. This model was based on a piecewise linear model, that is, linear splines with 3 knots; the knots are placed in $(1-0.5) / n, \ldots,(n-0.5) / n$ percentiles taken over the event data, where $n(=3)$ is the number of knots.

Confidence intervals and $p$ values for the quartiles are given as Wald estimates. Reported $p$ values are two-sided and the level of statistical significance was set a priori to 0.05. All analyses were performed using SAS software (version 
Table 2 Clinical characteristics at the patients first and last visit to the screening centre
Except where otherwise shown, data is given as median (interquartile range [IQR]) for the first visit at the screening centre and the last visit, defined as the last event-free visit for patients with event and the corresponding visit for patients without event

Statistical significance was assessed by Wilcoxon's test

\begin{tabular}{|c|c|c|c|}
\hline Variable & Never photocoagulated & Progressed to photocoagulation & $p$ value \\
\hline \multicolumn{4}{|l|}{ First screening visit } \\
\hline Patients included, $n(\%)$ & $1,581(84.19)$ & $297(15.81)$ & \\
\hline Male, $n(\%)$ & $824(52.12)$ & $156(52.53)$ & \\
\hline Age in years at onset of diabetes & $15.37(9.6,22.78)$ & $13.03(8.28,20.55)$ & 0.0005 \\
\hline Age in years at first screening visit & $32.15(24.96,42.38)$ & $39.77(31.26,45.61)$ & $<0.0001$ \\
\hline Duration of diabetes in years & $16.82(9.40,26.5)$ & $23.18(17.68,31.34)$ & $<0.0001$ \\
\hline $\mathrm{HbA}_{1 \mathrm{c}}, \%$ & $8.4(7.5,9.4)$ & $8.7(8.0,9.8)$ & 0.0010 \\
\hline $\mathrm{HbA}_{1 \mathrm{c}}, \mathrm{mmol} / \mathrm{mol}$ & $68.3(58.5,79.2)$ & $71.6(64.0,83.6)$ & \\
\hline Systolic blood pressure, $\mathrm{mmHg}$ & $130(118,142)$ & $137(125,150)$ & $<0.0001$ \\
\hline Diastolic blood pressure, $\mathrm{mmHg}$ & $80(70,85)$ & $84(78,90)$ & $<0.0001$ \\
\hline \multicolumn{4}{|l|}{ Last screening visit } \\
\hline Duration of diabetes in years & $25.89(17.00,35.71)$ & $31.62(24.68,39.36)$ & $<0.0001$ \\
\hline $\mathrm{HbA}_{1 \mathrm{c},} \%$ & $8.2(7.5,9.1)$ & $8.8(8.1,9.5)$ & $<0.0001$ \\
\hline $\mathrm{HbA}_{1 \mathrm{c}}, \mathrm{mmol} / \mathrm{mol}$ & $66.1(58.5,76.0)$ & $72.7(65.0,80.3)$ & \\
\hline Systolic blood pressure, $\mathrm{mmHg}$ & $131(120,145.5)$ & $136(127,152)$ & $<0.0001$ \\
\hline Diastolic blood pressure, $\mathrm{mmHg}$ & $78(70,85)$ & $80(72,88)$ & 0.0010 \\
\hline
\end{tabular}

9.2, SAS Institute, Cary NC, USA). This retrospective study did not require institutional review board approval under Danish law.

\section{Results}

Of the total population of 2,324 patients with type 1 diabetes, 1,878 were eligible for analysis. The median period of observation was 7.76 years, corresponding to a total follow-up of 15,431 patient-years, during which the patients had attended a mean of one screening visit per year. The median age was 33.4 years and the median duration of diabetes was 18.34 years at the patient's first retinopathy screening visit.

Progression to first photocoagulation treatment for CSME in a patient's first eye occurred in 297 patients. The total period of observation in patients who progressed to CSME was 7.36 years (median), compared with a median of 7.78 years in patients who did not progress to CSME $(p=0.057)$. We do, however, see a difference in the length of the last, event-free interval. In patients who were subsequently referred for photocoagulation for CSME the median length of the last interval was 0.63 years; in patients who did not develop CSME, the matching interval was 1.31 years $(p<0.0001)$.

Photocoagulation for CSME was carried out in 156 (15.9\%) of 980 men and in $141(15.7 \%)$ of 898 women $(p=0.9)$. Photocoagulation for CSME was most likely to be made after 30-40 years' duration of diabetes (Table 1).
First visit to the screening clinic At the first visit, patients who progressed to photocoagulation for CSME were younger at the onset of diabetes than patients who did not $(p=0.0005)$ but older at their first visit and therefore of longer diabetes duration when first seen at a retinopathy screening visit $(p<0.0001$; Table 2). No retinopathy, or mild background retinopathy with microaneurisms, were found at baseline in $76 \%$ of patients who did not receive photocoagulation for CSME vs $43 \%$ of patients who did; thus eyes that eventually progressed to photocoagulation for CSME had higher levels of retinopathy than eyes that did not $(p<0.0001)$. Photocoagulated proliferative retinopathy at baseline was present in less than $2 \%$ of the non-progressing patients vs 9\% of patients progressing to CSME.

As listed in Table 2, progression to photocoagulation was associated with higher $\mathrm{HbA}_{1 \mathrm{c}}$, higher systolic blood pressure and higher diastolic blood pressure at the first screening visit $(p<0.01)$ in separate non-parametric tests.

Relation to period of observation variables During the period of observation, median $\mathrm{HbA}_{1 \mathrm{c}}$ increased non-significantly from $8.7 \%$ to $8.8 \%$ ( 71.6 to $72.7 \mathrm{mmol} / \mathrm{l})$ in patients who progressed to photocoagulation for CSME ( $p>0.5$, Table 2) and decreased significantly from $8.4 \%$ to $8.2 \%$ (68.3 to $66.1 \mathrm{mmol} / \mathrm{l})$ in the remainder of the study population $(p<0.0001)$. Systolic blood pressure was stable for patients progressing to photocoagulation $(p=0.4)$, whereas a small increase was found in non-progressing patients. Diastolic blood pressure decreased significantly in both groups during the period of observation $(p<0.005$ and $p<0.01$ for progressing and non-progressing patients, respectively). 
Discrete time proportional hazards model Using a discrete time proportional hazards model, current values for $\mathrm{HbA}_{1 \mathrm{c}}$, systolic blood pressure and diastolic blood pressure remained significant risk factors for progression to photocoagulation for CSME $\left(\mathrm{HbA}_{1 \mathrm{c}} p<0.0001\right.$, systolic blood pressure $p=0.0003$, diastolic blood pressure $p=0.0038$, duration $p<0.0001$; Table 3, left column) when analysed separately and adjusted for current age, calendar period and duration (univariate model). With the same model, changes for both $\mathrm{HbA}_{1 \mathrm{c}}$, and systolic and diastolic blood pressure were all significant $(p<0.0001)$. In a multiple regression model containing all three covariates (joint model), only current $\mathrm{HbA}_{1 \mathrm{c}}$ remained significant overall ( $p<0.0001$; Table 3 , right column). For the effect of changes, both the change in $\mathrm{HbA}_{1 \mathrm{c}}$ and systolic blood pressure were significant $\left(\mathrm{HbA}_{1 \mathrm{c}}\right.$ change $p=0.0002$; systolic blood pressure $p<0.0001)$. Duration has both a linear and squared effect as the effect levels out after approximately 40 years duration (Fig. 1).

There was no effect of diabetes onset before or after puberty $(p>0.2)$ (results not shown). As shown in Table 3, upper and lower quartile changes in $\mathrm{HbA}_{1 \mathrm{c}}$ were associated with higher HRs for progression to CSME than the middle quartiles, irrespective of the change being a decrease or an increase (Table 3). The same U-pattern was found for changes in systolic and diastolic blood pressure. These effects of changes
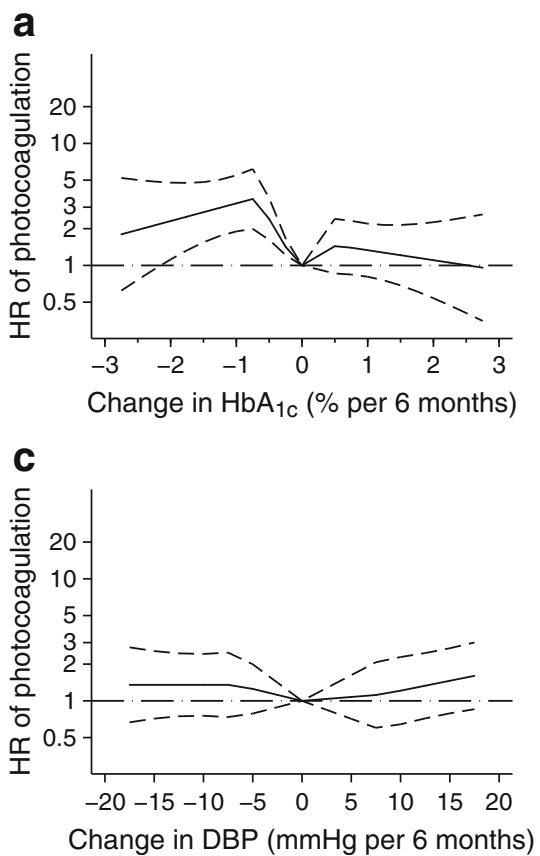

Fig. 1 (a-d) The effects of metabolic changes were entered into the models as continuous variables, as described in the Methods. The curves are calculated with a linear spline, i.e. a piecewise linear model, the HRs ( $\log _{\mathrm{e}}$ scale, solid line) and the $95 \%$ CIs (broken line) are shown from a joint model similar to Table 3. (a-c) For both $\mathrm{HbA}_{1 \mathrm{c}}$ and blood pressure, the minimal risk for photocoagulation was found for zero changes, with increasing risks both for decreases and increases in the variables. The in $\mathrm{HbA}_{1 \mathrm{c}}$ and systolic blood pressure remained significant in a joint, multiple regression model including current $\mathrm{HbA}_{1 \mathrm{c}}$ and blood pressure.

If analysed as continuous variables (Fig. 1) the HRs for $\mathrm{HbA}_{1 \mathrm{c}}$ and systolic and diastolic blood pressure follow the same pattern with minimal risk at zero change and fairly rapid increase with changes in both directions, followed by smaller effects on the risk for increasing changes. It should be noted that the graph is computed by a piecewise linear model, giving rise to distinct discontinuation points that do not reflect a similar clinical effect of the covariate.

In a separate analysis, the risk factors were re-evaluated including imputed values for the covariates. With this approach, all 1,878 patients with 297 events were included in the analysis. The HRs are summarised in Table 4 and show the same overall conclusion as the analysis based only on the observed data.

\section{Discussion}

In agreement with several previous reports, this study of a large diabetic retinopathy screening population found that the risk of diabetic retinopathy progression to a level that prompted photocoagulation for clinically significant macular oedema increased with increasing diabetes duration,
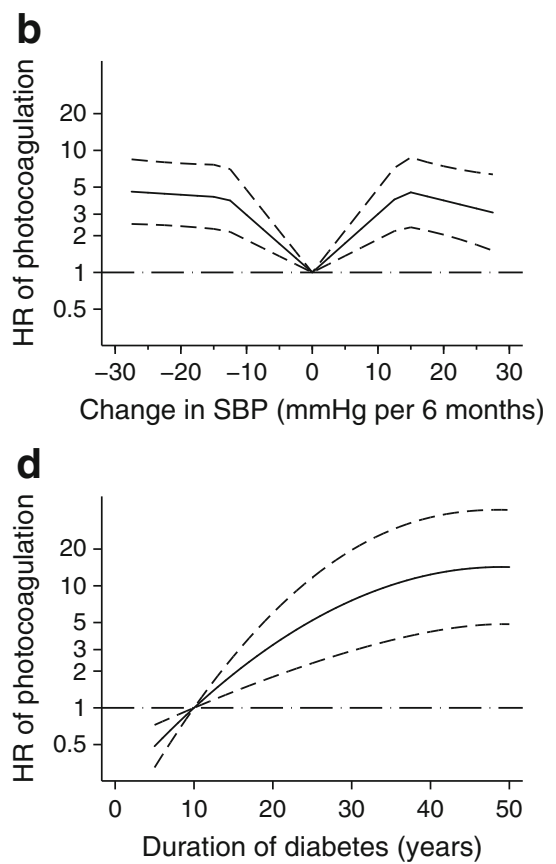

curves also suggest a peak in the hazard ratio for $\mathrm{HbA}_{1 \mathrm{c}}$ changes of 0.5 percentage points (corresponding to a change of $5.5 \mathrm{mmol} / \mathrm{mol}$ ) (a) and $10 \mathrm{mmHg}$ for systolic (b) and $5 \mathrm{mmHg}$ (c) for diastolic blood pressure, with a plateau for larger changes. Due to the piecewise linear model, the exact position of the peaks and the distinct discontinuation points should be interpreted with caution. The HR for diabetes duration (d) reaches a plateau after approximately 40 years 
Table 3 Effect of risk factors on the risk of progression to photocoagulation for CSME in patients with type 1 diabetes

\begin{tabular}{|c|c|c|c|c|c|c|c|}
\hline \multirow[t]{2}{*}{ Variable } & \multirow[t]{2}{*}{ Events } & \multicolumn{3}{|c|}{ Univariate } & \multicolumn{3}{|c|}{ Joint model } \\
\hline & & HR & $95 \% \mathrm{CI}$ & $p$ value & $\mathrm{HR}$ & $95 \% \mathrm{CI}$ & $p$ value \\
\hline Duration (years) & 297 & & & & & & \\
\hline Duration & & 1.18 & $1.11,1.26$ & $<0.0001$ & 1.18 & $1.07,1.30$ & 0.0011 \\
\hline Duration squared & & 0.998 & $0.997,0.99$ & 0.0001 & 0.998 & $0.997,1.00$ & 0.0262 \\
\hline Current $\mathrm{HbA}_{1 \mathrm{c}} \%$ & 257 & 1.34 & $1.22,1.47$ & $<0.0001$ & 1.49 & $1.30,1.70$ & $<0.0001$ \\
\hline Current SBP (per 10 mmHg) & 233 & 1.13 & $1.06,1.21$ & 0.0003 & 1.03 & $0.92,1.16$ & 0.5511 \\
\hline Current DBP (per 10 mmHg) & 233 & 1.22 & $1.07,1.39$ & 0.0038 & 1.04 & $0.84,1.29$ & 0.7094 \\
\hline Change in $\mathrm{HbA}_{1 \mathrm{c}} \%$ per 6 months & 211 & & & & & & \\
\hline$\leq-0.5$ & & 4.25 & $2.83,6.38$ & $<0.0001$ & 3.04 & $1.85,4.97$ & 0.0002 \\
\hline$>-0.5 \leq 0$ & & 1.46 & $1.01,2.11$ & & 1.37 & $0.88,2.13$ & \\
\hline$>0 \leq 0.5$ & & 1 & - & & 1 & - & \\
\hline$>0.5$ & & 2.84 & $1.85,4.43$ & & 1.28 & $0.76,2.16$ & \\
\hline Change in SBP per 6 months (mmHg) & 170 & & & & & & \\
\hline$\leq-10$ & & 3.09 & $1.96,4.86$ & $<0.0001$ & 2.59 & $1.50,4.48$ & $<0.0001$ \\
\hline$>-10 \leq 0$ & & 1.20 & $0.79,1.84$ & & 1.01 & $0.62,1.63$ & \\
\hline$>0 \leq 10$ & & 1 & - & & 1 & - & \\
\hline$>10$ & & 3.48 & $2.24,5.41$ & & 2.49 & $1.48,4.18$ & \\
\hline Change in DBP per 6 months (mmHg) & 170 & & & & & & \\
\hline$\leq-5$ & & 2.39 & $1.49,3.83$ & $<0.0001$ & 1.52 & $0.84,2.76$ & 0.3166 \\
\hline$>-5 \leq 0$ & & 1.39 & $0.91,2.14$ & & 1.47 & $0.90,2.39$ & \\
\hline$>0 \leq 5$ & & 1 & - & & 1 & - & \\
\hline$>5$ & & 2.52 & $1.57,4.02$ & & 1.51 & $0.88,2.61$ & \\
\hline
\end{tabular}

Models are adjusted for current year, age and duration of diabetes

Current $\mathrm{HbA}_{1 \mathrm{c}}$, systolic blood pressure (SBP) and diastolic blood pressure (DBP) are entered as continuous variables

For inter-visit changes in $\mathrm{HbA}_{1 \mathrm{c}}$ and blood pressure, the changes are expressed the change per 6 months, corresponding to the mean event-free interval preceding events. The changes are categorised and the HRs for progression to photocoagulation relative to the lowest scoring quartile are shown for each quartile of each descriptive variable

For $\mathrm{HbA}_{1 \mathrm{c}}$, the change per 6 month interval of 0.5 percentage points (pp) is equal to a change of $5.5 \mathrm{mmol} / \mathrm{mol}$

Because of missing data in the covariates the number of events in the joint model is less than in the univariate models (events in joint model=148)

glycaemia and blood pressure. The primary new information provided by this study is that large changes in glycaemia, systolic blood pressure and diastolic blood pressure occurring one retinopathy screening interval before progression to CSME, irrespective of whether they were decreases or increases, were independent risk factors for CSME.

The effect of $\mathrm{HbA}_{1 \mathrm{c}}$ change was studied in the 25 year follow-up of the Wisconsin Epidemiological Study of Diabetic Retinopathy. Based on 128 incident cases of clinically significant diabetic macular oedema it was found that CSME was associated with baseline $\mathrm{HbA}_{1 \mathrm{c}}$ and with the increase in $\mathrm{HbA}_{1 \mathrm{c}}$ from baseline to year 4. No effect of a decrease in $\mathrm{HbA}_{1 \mathrm{c}}$ was reported [12].

The DCCT found that, during the first year on intensified insulin therapy, progression of diabetic retinopathy was faster than with conventional insulin therapy [13-15]. Thus, although it was beneficial in the long run, a decrease in $\mathrm{HbA}_{1 \mathrm{c}}$ was associated with negative effects on an intermediate time scale. The DCCT study population had little retinopathy at baseline and few patients developed macular oedema during the study and at later follow-up (Epidemiology of Diabetes Interventions and Complications, EDIC), approximately $10 \%$ of the 1,208 patients had received focal photocoagulation [24]. $\mathrm{HbA}_{1 \mathrm{c}}$ variability measured in the DCCT study, but not glucose variability, was a significant risk factor for microvascular complications at the end of the EDIC study, but the timing of macular oedema was not analysed in relation to the magnitude and direction of changes in metabolic control [13-15].

The present study is the first large study to show that the sight-threatening event of incident CSME is associated with large changes in metabolic control. The finding that large changes in metabolic control or blood pressure increased the risk of CSME irrespective of direction was unanticipated.

In a clinical context it may be worth noting that the two middle quartiles that fared better with respect to progression to CSME were stable roughly within \pm 0.5 percentage point change in $\mathrm{HbA}_{1 \mathrm{c}}$ per 6 months, $\pm 10 \mathrm{mmHg}$ systolic blood pressure per 6 months and $\pm 5 \mathrm{mmHg}$ diastolic blood pressure 
Table 4 Sensitivity analysis of 297 events of progression to photocoagulation for CSME in patients with type 1 diabetes: the effect of risk factors based on imputed datasets for $\mathrm{HbA}_{1 \mathrm{c}}$ and blood pressure

\begin{tabular}{|c|c|c|c|c|c|c|c|}
\hline \multirow[t]{2}{*}{ Variable } & \multirow[t]{2}{*}{ Events $n=297$} & \multicolumn{3}{|c|}{ Univariate } & \multicolumn{3}{|c|}{ Joint model } \\
\hline & & HR & $95 \% \mathrm{CI}$ & $p$ value & HR & $95 \% \mathrm{CI}$ & $p$ value \\
\hline \multicolumn{8}{|l|}{ Duration (years) } \\
\hline Duration & & 1.18 & $1.11,1.26$ & $<0.0001$ & 1.15 & $1.07,1.22$ & $<0.0001$ \\
\hline Duration squared & & 0.998 & $0.997,0.99$ & 0.0001 & 0.998 & $0.998,0.99$ & 0.0012 \\
\hline Current $\mathrm{HbA}_{1 \mathrm{c}} \%$ & & 1.28 & $1.17,1.40$ & $<0.0001$ & 1.28 & $1.17,1.41$ & $<0.0001$ \\
\hline Current SBP (per 10 mmHg) & & 1.14 & $1.06,1.21$ & 0.0003 & 1.08 & $0.99,1.18$ & 0.0739 \\
\hline Current DBP (per 10 mmHg) & & 1.19 & $1.06,1.34$ & 0.0041 & 1.06 & $0.90,1.25$ & 0.4595 \\
\hline \multicolumn{8}{|c|}{ Change in $\mathrm{HbA}_{1 \mathrm{c}} \%$ per 6 months } \\
\hline$\leq-0.5$ & & 3.02 & $2.13,4.29$ & $<0.0001$ & 2.39 & $1.64,3.48$ & 0.0004 \\
\hline$>-0.5 \leq 0$ & & 1.43 & $1.01,2.00$ & & 1.59 & $1.11,2.26$ & \\
\hline$>0 \leq 0.5$ & & 1 & - & & 1 & - & \\
\hline$>0.5$ & & 2.61 & $1.80,3.80$ & & 1.49 & $0.98,2.25$ & \\
\hline \multicolumn{8}{|c|}{ Change in SBP per 6 months (mmHg) } \\
\hline$\leq-10$ & & 2.78 & $1.73,4.48$ & $<0.0001$ & 2.14 & $1.30,3.53$ & 0.0019 \\
\hline$>-10 \leq 0$ & & 1.08 & $0.68,1.70$ & & 1.12 & $0.70,1.77$ & \\
\hline $0 \leq 10$ & & 1 & - & & 1 & - & \\
\hline$>0$ & & 3.12 & $1.99,4.91$ & & 1.94 & $1.19,3.17$ & \\
\hline \multicolumn{8}{|c|}{ Change in DBP per 6 months (mmHg) } \\
\hline$\leq-5$ & & 2.40 & $1.54,3.73$ & $<0.0001$ & 1.60 & $0.99,2.59$ & 0.1143 \\
\hline$>-5 \leq 0$ & & 1.25 & $0.83,1.88$ & & 1.30 & $0.86,1.98$ & \\
\hline$>0 \leq 5$ & & 1 & - & & 1 & - & \\
\hline$>5$ & & 2.76 & $1.94,3.94$ & & 1.61 & $1.09,2.37$ & \\
\hline
\end{tabular}

The analysis includes imputed values for missing information on $\mathrm{HbA}_{1 \mathrm{c}}$, systolic blood pressure (SBP) and diastolic blood pressure (DBP)

For $\mathrm{HbA}_{1 \mathrm{c}}$, the change per 6 month interval of 0.5 percentage points (pp) is equal to a change of $5.5 \mathrm{mmol} / \mathrm{mol}$

The imputation is based on six imputed datasets and with this procedure, all 297 events are included in the analysis

per 6 months. Compared with these patients, the outer quartiles had a two- to threefold increased risk of CSME and with a quantitative analysis, the data indicates that relatively small changes rapidly increases the risk, followed by a plateau for large changes. The present study is a retrospective analysis, based on registrations in the screening centre database. Among other retrospective studies that may help guide endocrinology practice, Funatsu et al reported that, to minimise the risk of progression of retinopathy, the rate of change in $\mathrm{HbA}_{1 \mathrm{c}}$ should not exceed 2 percentage points over 6 months [25] while Ostri et al found that, to avoid diabetic papillopathy, rates of change in $\mathrm{HbA}_{1 \mathrm{c}}$ should not exceed -1.5 percentage points per quarter year [26]. It is difficult to compact these widely differing benchmarks into a single guideline figure for all types of retinopathy progression; however the estimates in the present study are fairly close to those of both Ostri et al and Funatsu et al. Given the imperative need to improve metabolic control in many patients with diabetes and the improved resources for management of diabetic macular oedema we support the conclusion of Funatsu et al and, as a clinical guideline, we venture to propose that the 6 month changes should be kept below the 2 percentage points for $\mathrm{HbA}_{1 \mathrm{c}}$ to minimise both progression of retinopathy and progression to clinically significant macular oedema.

Arterial hypertension is a documented risk factor for retinopathy $[10,11,13]$, which may be taken to suggest that a recent reduction in blood pressure should protect against CSME, but our finding of the opposite effect is not unprecedented. A randomised controlled clinical trial found that 4 months losartan therapy in diabetic macular oedema was associated with increased macular thickness compared to placebo [27]. We suspect that promotion of diabetic macular oedema by antihypertensive medications may result from the induction of retinal vasodilation and a consequent increase in capillary pressure.

The limitations of the present retrospective study include not having analysed the underlying causes of changes in glycaemia and blood pressure, be they intensified insulin therapy, concurrent systemic illness, progression of nephropathy with secondary arterial hypertension, intervention against nephropathy leading to a decrease in blood pressure, etc. Furthermore, we did not examine the effects of changes in 
cholesterol, triacylglycerol and other lipids on the risk of incident CSME [28].

In addition to confirming that duration of diabetes, high levels of glycaemia and high blood pressure are risk factors for progression of diabetic retinopathy, the present study found that large changes in glycaemia and systolic blood pressure were independent risk factors for progression to diabetic macular oedema in need of photocoagulation treatment. These observations indicate that the role of metabolic and haemodynamic stability in the development and progression of diabetic retinopathy should be examined in prospective studies.

Acknowledgements I. Skovgaard from the Institute of Biostatistics and Mathematics, University of Copenhagen, is thanked for assistance regarding the statistical analysis.

Funding The study was supported by the Novo Nordisk Foundation, the VELUX Foundation and the Danish Council for Independent Research, Medical Sciences (grant no. 09-071219).

Duality of interest The authors declare that there is no duality of interest associated with this manuscript.

Contribution statement BS, ML and HLA were involved in the conception and design of the study. The data were analysed by BS and EWA and interpreted by all authors. All authors drafted the paper and revised it critically for important intellectual content. All authors gave their final approval of the current version to be published.

Open Access This article is distributed under the terms of the Creative Commons Attribution Noncommercial License which permits any noncommercial use, distribution, and reproduction in any medium, provided the original author(s) and the source are credited.

\section{References}

1. Moss SE, Klein R, Klein BE (1998) The 14-year incidence of visual loss in a diabetic population. Ophthalmology 105:998-1003

2. Grauslund J, Green A, Sjølie AK (2009) Blindness in a 25-year follow-up of a population-based cohort of Danish type 1 diabetic patients. Ophthalmology 116:2170-2174

3. Sander B, Thornit DN, Colmorn L et al (2007) Progression of diabetic macular edema: correlation with blood retinal barrier permeability, retinal thickness, and retinal vessel diameter. Invest Ophthalmol Vis Sci 48:3983-3987

4. Sander B, Hamann P, Larsen M (2008) A 5-year follow-up of photocoagulation in diabetic macular edema: the prognostic value of vascular leakage for visual loss. Graefes Arch Clin Exp Ophthalmol 246:1535-1539

5. Lövestam-Adrian M, Agardh C-D, Torfvit O, Agardh E (2001) Diabetic retinopathy, visual acuity, and medical risk indicators. A continuous 10-year follow-up study in Type 1 diabetic patients under routine care. J Diab Compl 15:287-294

6. Reichard P, Pihl M, Rosenqvist U, Sule J (1996) Complications in IDDM are caused by elevated blood glucose level: the Stockholm Diabetes Intervention Study (SDIS) at 10-year follow up. Diabetologia 39:1483-1488

7. Gaede P, Lund-Andersen H, Parving HH, Pedersen O (2008) Effect of a multifactorial intervention on mortality in type 2 diabetes. N Engl J Med 358:580-591
8. Lund-Andersen C, Frost-Larsen K, Starup K (1987) Natural history of diabetic retinopathy in insulin-dependent juvenile diabetics. A longitudinal study. Acta Ophthalmol (Copenh) 65:481-486

9. Grauslund J, Green A, Sjolie AK (2009) Prevalence and 25 year incidence of proliferative retinopathy among Danish type 1 diabetic patients. Diabetologia 52:1829-1835

10. Klein R, Klein BE, Moss SE, Davis MD, DeMets DL (1984) The Wisconsin epidemiologic study of diabetic retinopathy. IV. Diabetic macular edema. Ophthalmology 91:1464-1474

11. Klein R, Klein BE, Moss SE, Davis MD, DeMets DL (1989) The Wisconsin Epidemiologic Study of Diabetic Retinopathy. IX. Fouryear incidence and progression of diabetic retinopathy when age at diagnosis is less than 30 years. Arch Ophthalmol 107:237-243

12. Klein R, Knudtson MD, Lee KE, Gangnon R, Klein BE (2009) The Wisconsin Epidemiologic Study of Diabetic Retinopathy XXIII: the twenty-five-year incidence of macular edema in persons with type 1 diabetes. Ophthalmology 116:497-503

13. DCCT/EDIC Research Group (1993) The effect of intensive treatment of diabetes on the development and progression of long-term complications in insulin-dependent diabetes mellitus. The Diabetes Control and Complications Trial Research Group. N Engl J Med 329:977-986

14. DCCT/EDIC Research Group (1998) Early worsening of diabetic retinopathy in the Diabetes Control and Complications Trial. Arch Ophthalmol 116:874-886

15. DCCT/EDIC Research Group (2002) Effect of intensive therapy on the microvascular complications of type 1 diabetes mellitus. JAMA 287:2563-2569

16. Kilpatrick ES, Rigby AS, Atkin SL (2006) The effect of glucose variability on the risk of microvascular complications in type 1 diabetes. Diabetes Care 29:1486-1490

17. Kilpatrick ES, Rigby AS, Atkin SL (2008) Alc variability and the risk of microvascular complications in type 1 diabetes: data from the diabetes control and complications trial. Diabetes Care 31:2198-2202

18. Hansen AB, Sander B, Larsen M et al (2004) Screening for diabetic retinopathy using a digital non-mydriatic camera compared with standard 35-mm stereo colour transparencies. Acta Ophthalmol Scand 82:656-665

19. ETDRS Research Group (1985) Photocoagulation for diabetic macular edema: ETDRS report number 1. Arch Ophthalmol 103:1796-1806

20. ETDRS Research Group (1987) Treatment techniques and clinical guidelines for photocoagulation of diabetic macular edema: ETDRS report number 2. Ophthalmology 94:761-774

21. Klein R, Klein BE, Moss SE, Davis MD, DeMets DL (1985) Retinopathy in young-onset diabetic patients. Diabetes Care 8:311-315

22. Olsen BS, Sjolie AK, Hougaard P et al (2004) The significance of the prepubertal diabetes duration for the development of retinopathy and nephropathy in patients with type 1 diabetes. J Diabetes Complicat 18:160-164

23. Prentice RL, Kalbfleisch JD (2003) Mixed discrete and continuous Cox regression model. Lifetime Data Anal 9:195-210

24. DCCT/EDIC Research Group (2000) Retinopathy and nephropathy in patients with type 1 diabetes 4 years after a trial of intensive therapy. N Engl J Med 342:381-389

25. Funatsu H, Yamashita H, Ohashi Y, Ishigaki T (1992) Effect of rapid glycemic control on progression of diabetic retinopathy. Jpn J Ophthalmol 36:356-367

26. Ostri C, Lund-Andersen H, Sander B, Hvidt-Nielsen D, Larsen M (2010) Bilateral diabetic papillopathy and metabolic control. Ophthalmology 117:2214-2217

27. Knudsen ST, Bek T, Poulsen PL, Hove MN, Rehling M, Mogensen CE (2003) Effects of losartan on diabetic maculopathy in type 2 diabetic patients: a randomized, double-masked study. J Intern Med 254(2):147-158

28. Benarous R, Sasongko MB, Qureshi S et al (2011) Differential association of serum lipids with diabetic retinopathy and diabetic macular edema. Invest Ophthalmol Vis Sci 52:7464-7469 